\title{
Mathematical Modeling of Thermoelastic State of a Functionally Graded Thermally Sensitive Thick Hollow Cylinder with Internal Heat Generation
}

\author{
V. R. Manthena ${ }^{1 *}$, G. D. Kedar ${ }^{2}$ \\ ${ }^{1}$ Department of Mathematics, Priyadarshini J. L. College of Engineering, Nagpur, India. \\ ${ }^{2}$ Department of Mathematics, RTM Nagpur University, Nagpur, India. \\ E-mail:1kmanthena@gmail.com, ${ }^{2}$ gdkedar@ rediffmail.co.in
}

Received 15June 2018, Revised 02October 2018, Accepted 10October 2018

\begin{abstract}
In this paper, the effect of internal heat generation has been studied in a functionally graded (FG) thick hollow cylinder in context with thermosensitive thermoelastic properties. Initially, the cylinder is kept at reference temperature and the radial boundary surface under consideration dissipates heat by convection according to Newton's law of cooling, heat flux is applied at the lower surface, while the upper surface is insulated. The heat conduction equation due to internal heat generation is solved by integral transform technique and Kirchhoff's variable transformation is used to deal with the nonlinearity of the heat conduction equation. A mathematical model has been constructed for a nonhomogeneous material in which the material properties are assumed to be dependent on both temperature and spatial variable z. A ceramic-metal-based FG material is considered in which alumina is selected as ceramic and nickel as metal. The results obtained are illustrated graphically.
\end{abstract}

Keywords:Thick hollow cylinder; Functionally graded material; Heat conduction; Thermal stresses; Thermosensitive; Kirchhoff's variable; Internal heat generation.

\section{Introduction}

Materials with changing composition, microstructure, or porosity across the volume of the material are referred to as the functionally graded materials (FGMs). FGMs are designed with changing properties over the volume of the bulk material, with the aim of performing a set of specified functions. The concept of FGM is to make a composite material by varying the microstructure from one material to another material with a specific gradient. This enables the material to have the best of both materials. Thermally sensitive materials are capable to alter the state or release significant amounts of energy during melting process, solidification or sublimation. These materials absorb energy during the heating process when the phase change takes place and in case of cooling process energy can be transferred to the environment while returning to the initial phase. Therefore, the study of thermosensitivity is extremely important for the determination of the temperature distribution and thermal stresses of cylindrical structures made of FGMs.

Tang, Hata, Noda et al. [1-4,7] obtained the solution of thermal-stress distribution in a nonhomogeneous medium and discussed thermoelastic problems in materials with temperature dependent properties in various solids. Popovych et al. [5,6] constructed solutions of heatconduction problems for thermosensitive bodies with convective heat transfer using analytical-numerical methods. Miyamoto et al. and Mahamood et al. [8,16] briefly explained the design, processing and applications of FGMs. Awaji et al. [9] presented a numerical technique for analyzing one-dimensional transient temperature and stress distributions in a stress-relief-type plate of functionally graded ceramic-metal based FGMs. Kawasaki and Watanabe [10] evaluated Thermal fracture behavior of metal/ceramic FGMs by a well controlled burner heating method using a $\mathrm{H} 2 / \mathrm{O} 2$ combustion flame. Al-Hajri and Kalla [11] developed a new integral transform involving a combination of Bessel's function as a kernel to solve some mixed boundary value problems in infinite and semiinfinite cylinders with radiation type boundary conditions. Kushnir, Guo [12,13,15] studied the thermal stresses of a thin functionally graded material (FGM) cylindrical shell subjected to a thermal shock. Kedar and Deshmukh [14] studied the temperature distribution of a thick circular plate. Sharma et al. [17] studied finite element analysis of thermoelastic stresses, displacements and strains in a thin circular functionally graded material (FGM) disk subjected to thermal loads. Moosaie, Nikolarakis, Eraslan, Raocha $[18,19,20,22]$ studied thermoelastic problems on circular bodies. Manthena et al. [21,23,24,28,30,31] developed mathematical models of thermoelasticity for rectangular plates and hollow circular cylinders. Bhad, Surana, Tripathi, Köbler [25,26,27,29] studied thermal stresses in elliptical and cylindrical bodies.

In ample of cases, it was observed that, the heat production in solids have lead to various technical problems during mechanical applications in which heat is generated and rapidly transferred from their surface. Temperature dependent FGMs are ideal for reducing the mismatch in the thermo-mechanical properties in metalceramic bonding that help to prevent debonding. FGMs have wide applications where extraordinary mechanical, thermal, and chemical properties are required which must be able to sustain severe working environments. These 
potential future application areas include applications, where the structural and the engineering uses require a combination of incompatible functions, such as hardness and toughness. Most of the authors mentioned above, have studied heat conduction and its associated thermal stresses for a medium with temperature dependent and independent material properties. However, it is observed that thermal effects due to internal heat generation with instantaneous point heat source have not been analyzed till date.

In this paper, we have extended our own work Manthena and Kedar [31] by considering internal heat generation in the heat conduction equation and studied a transient thermoelastic problem of a thick hollow cylinder, occupying the space defined as $a \leq r \leq b, 0 \leq z \leq h$, subjected to instantaneous point heat source. All the material properties except Poisson's ratio are assumed to be dependent on both temperature and spatial variablez. The heat conduction equation is solved by introducing Kirchhoff's variable transformation and transient state solution is obtained in the form of Bessel's and trigonometric functions.

\section{Statement of the Problem}

The temperature and spatial variable dependent transient heat conduction equation with internal heat generation of a FG thick hollow cylinder is

$$
\begin{aligned}
& \frac{1}{r} \frac{\partial}{\partial r}\left(r k(z, T) \frac{\partial T}{\partial r}\right)+\frac{\partial}{\partial z}\left(k(z, T) \frac{\partial T}{\partial z}\right) \\
& +g(r, z, t)=C(z, T) \frac{\partial T}{\partial t}
\end{aligned}
$$

The initial and boundary conditions are

$$
\begin{array}{ll}
T=T_{0}, & \text { at } t=0 \\
k(z, T) \frac{\partial T}{\partial r}-\varepsilon_{1}\left(T-T_{0}\right)=f_{1}(z, t), & \text { at } r=a \\
k(z, T) \frac{\partial T}{\partial r}+\varepsilon_{2}\left(T-T_{0}\right)=f_{1}(z, t), & \text { at } r=b \\
k(z, T) \frac{\partial T}{\partial z}=f_{2}(r, t), & \text { at } z=0 \\
\frac{\partial T}{\partial z}=0, & \text { at } z=h
\end{array}
$$

where $k(z, T)$ and $C(z, T)$ are the thermal conductivity and specific heat capacity, which are dependent on temperature and spatial variable $z, g(r, z, t)$ is the internal heat generation, $T_{0}$ is the temperature of the surrounding medium, and $\varepsilon_{1}, \varepsilon_{2}$ are the heat transfer coefficients.

The strain displacement relations and equilibrium conditions are given by Hata [2]

$$
\begin{aligned}
& \varepsilon_{r r}=\frac{\partial u}{\partial r}, \quad \varepsilon_{\theta \theta}=\frac{u}{r}, \quad \varepsilon_{z z}=\frac{\partial w}{\partial z}, \\
& \varepsilon_{r z}=\frac{1}{2}\left(\frac{\partial u}{\partial z}+\frac{\partial w}{\partial r}\right)
\end{aligned}
$$

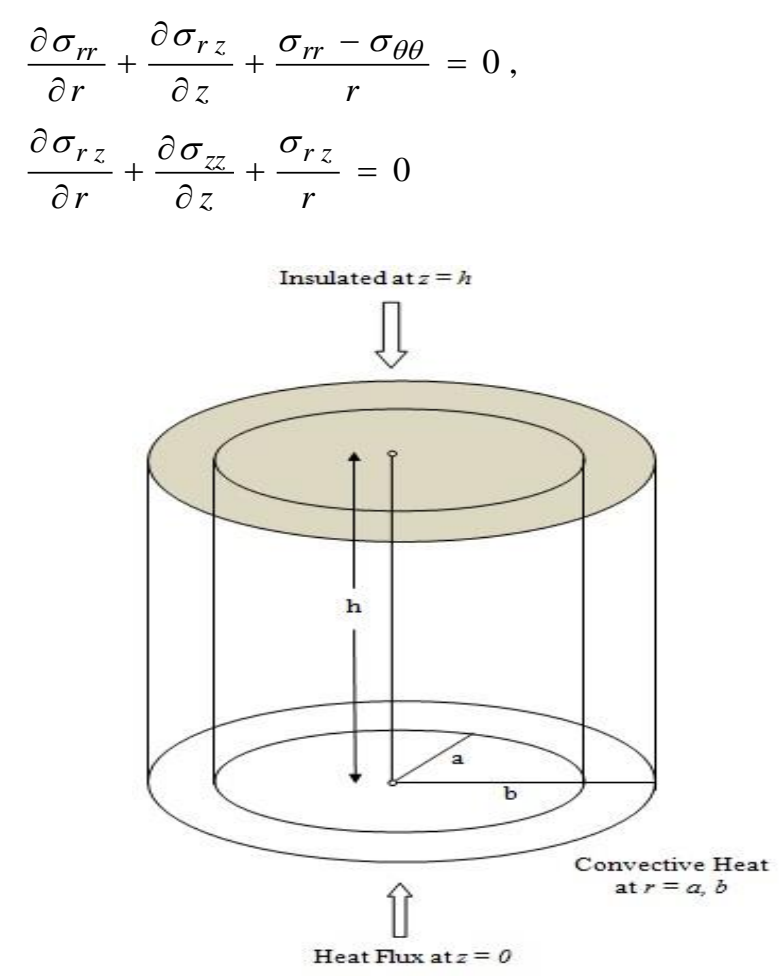

Figure 1. Geometrical representation of the problem.

The stress-strain relations with temperature dependent material properties are

$$
\begin{aligned}
\sigma_{r r}= & 2 G(z, T) \varepsilon_{r r}+\lambda(z, T) \varepsilon \\
& -(3 \lambda(z, T)+2 \mu(z, T)) \alpha_{T}(z, T) T \\
\sigma_{\theta \theta}= & 2 G(z, T) \varepsilon_{\theta \theta}+\lambda(z, T) \varepsilon \\
& -(3 \lambda(z, T)+2 \mu(z, T)) \alpha_{T}(z, T) T \\
\sigma_{z z}= & 2 G(z, T) \varepsilon_{z z}+\lambda(z, T) \varepsilon \\
- & (3 \lambda(z, T)+2 \mu(z, T)) \alpha_{T}(z, T) T \\
\sigma_{r z}= & 2 G(z, T) \varepsilon_{r z}
\end{aligned}
$$

where $\varepsilon_{r r}, \varepsilon_{\theta \theta}, \varepsilon_{z z}$ are the strain components $\left(\varepsilon=\varepsilon_{r r}+\varepsilon_{\theta \theta}+\varepsilon_{z z}\right), G(z, T)$ is the shear modulus, $\lambda(z, T)$ and $\mu(z, T)$ are Lame's constants, $\alpha_{T}(z, T)$ is the coefficient of thermal expansion. For the sake of brevity, the shear modulus $G(z, T)$, coefficient of thermal expansion $\alpha_{T}(z, T)$ and Lame's constant $\lambda(z, T)$ and $\mu(z, T)$ are assumed as

$$
\begin{aligned}
& G(z, T)=G_{0} z^{\beta} \exp (\varpi T), \\
& \alpha_{T}(z, T)=\alpha_{0} z^{\beta} \exp (\chi T), \\
& \lambda(z, T)=\lambda_{o} z^{\beta} \exp (\varpi T), \\
& \mu(z, T)=\mu_{0} z^{\beta} \exp (\varpi T), \varpi \leq 0, \chi \geq 0
\end{aligned}
$$

where $G_{0}, \alpha_{0}$ and $\lambda_{0}, \mu_{0}$ are the reference values of shear modulus, coefficient of thermal expansion and Lame's constant respectively, $\beta$ is the inhomogeneity parameter.

Using Eqs. (3), (5), (6) in Eq. (4), the displacement equations of equilibrium are obtained as 


$$
\begin{aligned}
& \nabla^{2} u-\frac{u}{r^{2}}+\varpi \frac{\partial u}{\partial r} \frac{\partial T}{\partial r}+\frac{\lambda_{0}}{2 G_{0} \mu_{0}}\left(\frac{\partial \varepsilon}{\partial r}+\varepsilon \varpi \frac{\partial T}{\partial r}\right) \\
& +\frac{\partial^{2} w}{\partial r \partial z}+\left(\frac{\partial u}{\partial z}+\frac{\partial w}{\partial r}\right)\left(\varpi \frac{\partial T}{\partial z}+\frac{\beta}{z}\right) \\
& -\alpha_{0}\left(\frac{3 \lambda_{0}}{2 \mu_{0}}+1\right) z^{\beta} \exp (\chi T) \frac{\partial T}{\partial r}(\varpi T+1+T)=0 \\
& \nabla^{2} w+\frac{\partial^{2} u}{\partial r \partial z}+\left(\frac{\partial u}{\partial z}+\frac{\partial w}{\partial r}\right)\left(\varpi \frac{\partial T}{\partial r}+\frac{1}{r}\right) \\
& +\left(\varpi \frac{\partial T}{\partial z}+\frac{\beta}{z}\right)\left(\frac{\partial w}{\partial z}+\frac{\lambda_{0} \varepsilon}{\mu_{0}}\right)+\frac{\lambda_{0}}{G_{0} \mu_{0}} \frac{\partial \varepsilon}{\partial z} \\
& -\alpha_{0}\left(\frac{3 \lambda_{0}}{2 \mu_{0}}+1\right) z^{\beta} \exp (\chi T) \varpi T=0
\end{aligned}
$$

where

$$
\nabla^{2}=\left(\partial^{2} / \partial r^{2}\right)+(1 / r)(\partial / \partial r)+\left(\partial^{2} / \partial z^{2}\right)(8)
$$

The solution of Eq. (5) without body forces can be expressed by the Goodier's thermoelastic displacement potential $\phi$ and the Boussinesq harmonic functions $\varphi$ and $\psi$ as

$u=\frac{\partial \phi}{\partial r}+\frac{\partial \varphi}{\partial r}+z \frac{\partial \psi}{\partial r}$

$w=\frac{\partial \phi}{\partial z}+\frac{\partial \varphi}{\partial z}+z \frac{\partial \psi}{\partial z}-(3-4 v) \psi$

in which the three functions $\phi, \varphi, \psi$ must satisfy the conditions

$\nabla^{2} \phi=K \tau, \nabla^{2} \varphi=0$ and $\nabla^{2} \psi=0$

where $K(z, T)=[(1+v) /(1-v)] \alpha_{T}(z, T)$ is the restraint coefficient and $\tau=T-T_{0}$.

If we take

$$
-\int(\varphi+z \psi) d z=M(11)
$$

in the above Eq. (9), Michell's function $M$ may be used instead of Boussinesq harmonic functions $\varphi$ and $\psi$.

Hence Eq. (9) reduces to

$$
\begin{aligned}
& u=\frac{\partial \phi}{\partial r}-\frac{\partial^{2} M}{\partial r \partial z}, \\
& w=\frac{\partial \phi}{\partial z}+2(1-v) \nabla^{2} M-\frac{\partial^{2} M}{\partial z^{2}}
\end{aligned}
$$

in which Michell's function $M$ must satisfy the condition

$$
\nabla^{2} \nabla^{2} M=0
$$

Now by using Eq. (12) in Eq. (5), the results for stresses are obtained as

$$
\begin{gathered}
\sigma_{r r}=z^{\beta} \exp (\varpi T)\left\{\begin{array}{l}
2 G_{0} \frac{\partial}{\partial r}\left(\frac{\partial \phi}{\partial r}-\frac{\partial^{2} M}{\partial r \partial z}\right) \\
+\lambda_{0}\left[\nabla^{2} \phi+(1-2 v) \frac{\partial}{\partial z}\left(\nabla^{2} M\right)\right] \\
-\left(3 \lambda_{0}+2 \mu_{0}\right) \alpha_{0} z^{\beta} \exp (\chi T) T
\end{array}\right\} \\
\sigma_{\theta \theta}=z^{\beta} \exp (\varpi T)\left\{\begin{array}{l}
+\lambda_{0}\left[\nabla^{2} \phi+(1-2 v) \frac{\partial}{\partial z}\left(\nabla^{2} M\right)\right] \\
-\left(3 \lambda_{0}+2 \mu_{0}\right) \alpha_{0} z^{\beta} \exp (\chi T) T
\end{array}\right\} \\
\sigma_{z z}=z^{\beta} \exp (\varpi T)\left\{\begin{array}{l}
\left.\frac{\partial}{\partial r}-\frac{\partial^{2} M}{\partial r \partial z}\right) \\
2 G_{0} \frac{\partial}{\partial z}\left(\frac{\partial \phi}{\partial z}+2(1-v) \nabla^{2} M-\frac{\partial^{2} M}{\partial z^{2}}\right) \\
+\lambda_{0}\left[\nabla^{2} \phi+(1-2 v) \frac{\partial}{\partial z}\left(\nabla^{2} M\right)\right]
\end{array}\right\} \\
-\left(3 \lambda_{0}+2 \mu_{0}\right) \alpha_{0} z^{\beta} \exp (\varpi T) \exp (\chi T) T \\
{\left[\begin{array}{l}
\frac{\partial}{\partial z}\left(\frac{\partial \phi}{\partial r}-\frac{\partial^{2} M}{\partial r \partial z}\right) \\
+\frac{\partial}{\partial r}\left(\frac{\partial \phi}{\partial z}+2(1-v) \nabla^{2} M-\frac{\partial^{2} M}{\partial z^{2}}\right)
\end{array}\right]}
\end{gathered}
$$

The boundary conditions on the traction free surface stress functions are

$$
\begin{aligned}
& \sigma_{r r}=0 \text {, at } r=a \text { and } r=b \\
& \sigma_{z z}=0 \text {, at } z=0 \text { and } z=h
\end{aligned}
$$

\section{Solution of the Problem}

Following Noda [3], the thermal conductivity $k(z, T)$ and specific heat capacity $C(z, T)$ are taken as

$$
k(z, T)=z^{\beta} k(T), C(z, T)=z^{\beta} C(T)(16)
$$

Using Eq.(16) and intruding the Kirchhoff's variable following Popovych et al. [6, 12, 15, 22]

$$
\Theta(T)=\int_{T_{0}}^{T} k(z, T) d T(17)
$$

and taking into account that the material with simple thermal nonlinearity $((C(T) / k(T)) \approx 1)$ is considered, we obtain Eq. (1) with variable $\Theta$ as

$$
\left(\frac{\partial^{2} \Theta}{\partial r^{2}}+\frac{1}{r} \frac{\partial \Theta}{\partial r}\right)+\frac{\partial^{2} \Theta}{\partial z^{2}}+g(r, z, t)=\frac{\partial \Theta}{\partial t}
$$

The initial and boundary conditions (2) become 
$\Theta=0$,

$$
\text { at } t=0
$$

$\frac{\partial \Theta}{\partial r}-\varepsilon_{1} \Theta=f_{1}(z, t), \quad$ at $r=a$

$\frac{\partial \Theta}{\partial r}+\varepsilon_{2} \Theta=f_{1}(z, t), \quad$ at $r=b$

$\frac{\partial \Theta}{\partial z}=f_{2}(r, t), \quad$ at $z=0$

$\frac{\partial \Theta}{\partial z}=0, \quad$ at $z=h$

For the sake of brevity, we take

$g(r, z, t)=Q_{0} \delta\left(r-r_{0}\right) \delta\left(z-z_{0}\right) \delta(t)$,

$f_{1}(z, t)=Q_{1} \delta\left(z-z_{0}\right) \sinh \left(\omega_{1} t\right)$,

$f_{2}(r, t)=Q_{2} \delta\left(r-r_{0}\right) \sinh \left(\omega_{1} t\right)$.

Here $g(r, z, t)$ represents an instantaneous point heat source at the point $\left(r=r_{0}, z=z_{0}\right)$ of strength $Q_{0}, f_{1}(z, t)$ and $f_{2}(r, t)$ represent exponentially varying point heat at the points $\left(r=a, z=z_{0}\right),\left(r=b, z=z_{0}\right) \quad$ and ( $\left.r=r_{0}, z=0\right)$ of strengths $Q_{1}$ and $Q_{2}$ respectively.

Using the transform given by Al-Hajri and Kalla [11] to solve the Eq. (18) over the variable $r$, we obtain

$A_{1} \delta\left(z-z_{0}\right) \sinh \left(\omega_{1} t\right)-q_{n}^{2} \bar{\Theta}+\frac{\partial^{2} \bar{\Theta}}{\partial z^{2}}$

$+\bar{g}\left(q_{n}, z, t\right)=\frac{\partial \bar{\Theta}}{\partial t}$

where

$A_{1}=b \varepsilon_{2} M\left(q_{n} b\right) Q_{1}-a \varepsilon_{1} M\left(q_{n} a\right) Q_{1}$,

$\bar{g}\left(q_{n}, z, t\right)=Q_{0} r_{0} M\left(q_{n} r_{0}\right) \delta\left(z-z_{0}\right) \delta(t)$.

The initial and boundary conditions (19) become

$\bar{\Theta}=0, \quad$ at $t=0$

$\frac{\partial \bar{\Theta}}{\partial z}=\bar{f}_{2}\left(q_{n}, t\right), \quad$ at $z=0$

$\frac{\partial \bar{\Theta}}{\partial z}=0, \quad$ at $z=h$

where

$\bar{f}_{2}\left(q_{n}, t\right)=Q_{2} r_{0} M\left(q_{n} r_{0}\right) \sinh \left(\omega_{1} t\right)$

Here $M\left(q_{n} r\right)$ is the kernel of the transformation given by

$$
\begin{aligned}
M\left(q_{n} r\right)= & {\left[B\left(q_{n} a,-\varepsilon_{1}\right)+B\left(q_{n} b, \varepsilon_{2}\right)\right] J_{0}\left(q_{n} r\right) } \\
& -\left[A\left(q_{n} a,-\varepsilon_{1}\right)+A\left(q_{n} b, \varepsilon_{2}\right)\right] Y_{0}\left(q_{n} r\right)
\end{aligned}
$$

in which

$$
\begin{aligned}
& A\left(q_{n} r, \varepsilon_{n 1}\right)=\varepsilon_{n 1} J_{0}\left(q_{n} r\right)+q_{n} J_{0}{ }^{\prime}\left(q_{n} r\right) ; \\
& n 1=1,2 ; r=a, b \\
& B\left(q_{n} r, \varepsilon_{n 1}\right)=\varepsilon_{n 1} Y_{0}\left(q_{n} r\right)+q_{n} Y_{0}^{\prime}\left(q_{n} r\right)
\end{aligned}
$$

Here $J_{0}$ and $Y_{0}$ are Bessel's function of first and second kind, respectively, $q_{n}$ are the positive roots of the transcendental equation

$$
\begin{aligned}
& B\left(q_{n} a,-\varepsilon_{1}\right) \times A\left(q_{n} b, \varepsilon_{2}\right) \\
& -A\left(q_{n} a,-\varepsilon_{1}\right) \times B\left(q_{n} b, \varepsilon_{2}\right)=0 .
\end{aligned}
$$

Applying finite Fourier Cosine transform on Eq. (21) over the variable $z$, we obtain

$\frac{\partial \overline{\bar{\Theta}}}{\partial t}+A_{3} \overline{\bar{\Theta}}=A_{2} \sinh \left(\omega_{1} t\right)+A_{4} \delta(t)$

The initial condition is

$\overline{\bar{\Theta}}=0$,

$$
\text { at } t=0
$$

where

$$
\begin{aligned}
A_{2}= & A_{1}(\sqrt{2 / \pi}) \cos \left(m \pi z_{0} / h\right) \theta *\left(z_{0}\right) \\
& +Q_{2} r_{0} M\left(q_{n} r_{0}\right), A_{3}=\left(q_{n}^{2}+\alpha_{m}^{2}\right), \\
A_{4} & =-Q_{0} r_{0} M\left(q_{n} r_{0}\right)(\sqrt{2 / \pi}) \cos \left(m \pi z_{0} / h\right) \theta^{*}\left(z_{0}\right) .
\end{aligned}
$$

Here $\theta^{*}\left(z_{0}\right)$ is the Heaviside Theta function

$$
\theta *\left(z_{0}\right)= \begin{cases}0 ; & z_{0}<0 \\ 1 ; & z_{0} \geq 0\end{cases}
$$

Applying Laplace transform and its inverse on Eq. (24) by using the initial condition given in Eq. (25), we obtain

$$
\begin{aligned}
\overline{\bar{\Theta}}(t)= & \left(E_{1}+A_{4}\right) \exp \left(-A_{3} t\right)+E_{2} \exp \left(-\omega_{1} t\right) \\
& +E_{3} \exp \left(\omega_{1} t\right)
\end{aligned}
$$

where

$$
E_{1}=\frac{A_{2} \omega_{1}}{A_{3}^{2}-\omega_{1}^{2}}, E_{2}=\frac{A_{2}}{2 \omega_{1}-2 A_{3}}, E_{3}=\frac{A_{2}}{2 \omega_{1}+2 A_{3}}
$$

Applying inverse Fourier Cosine transform on Eq. (26), we get

$$
\bar{\Theta}(z, t)=\frac{\left[\xi_{1}(t)\right]_{m=0}}{h}+\sum_{m=1}^{\infty}\left\{\xi_{1}(t) \times \cos (m \pi z / h)\right\}
$$

where

$$
\begin{aligned}
\xi_{1}(t)= & \left(E_{1}+A_{4}\right) \exp \left(-A_{3} t\right)+E_{2} \exp \left(-\omega_{1} t\right) \\
& +E_{3} \exp \left(\omega_{1} t\right)
\end{aligned}
$$

Applying inverse transform given by Al-Hajri and Kalla [11] on the above Eq. (27), we obtain 


$$
\begin{aligned}
\Theta(r, z, t)= & \sum_{n=1}^{\infty}\left\{\left(\left[\xi_{1}(t)\right]_{m=0} / h\right)\right. \\
& +\sum_{m=1}^{\infty}\left\{\xi_{1}(t) \times \cos (m \pi z / h)\right\} \\
& \left.\times\left[\xi_{2} J_{0}\left(q_{n} r\right)-\xi_{3} Y_{0}\left(q_{n} r\right)\right]\right\}
\end{aligned}
$$

where

$$
\begin{aligned}
& \xi_{2}=\left(1 /\left[M\left(q_{n}\right)\right]\right)\left[B\left(q_{n} a,-\varepsilon_{1}\right)+B\left(q_{n} b, \varepsilon_{2}\right)\right], \\
& \xi_{3}=\left(1 /\left[M\left(q_{n}\right)\right]\right)\left[A\left(q_{n} a,-\varepsilon_{1}\right)+A\left(q_{n} b, \varepsilon_{2}\right)\right], \\
& \int_{a}^{b} r M\left(q_{n} r\right) M\left(q_{m} r\right) d r= \begin{cases}M\left(q_{n}\right) ; & m=n \\
0 ; & m \neq n\end{cases}
\end{aligned}
$$

Applying variable inverse transformation from $\Theta$ to $T$ [see Appendix A], the temperature distribution in Eq. (28) becomes

$$
\begin{aligned}
& T(r, z, t) \cong T_{0}+\sum_{n=1}^{\infty}\left[1 / \exp \left(\varpi T_{0}\right)\right] \\
& \times[1 / u(z)]\left\{\left(\left[\xi_{1}(t)\right]_{m=0} / h\right)\right. \\
& +\sum_{m=1}^{\infty}\left\{\xi_{1}(t) \times \cos (m \pi z / h)\right\} \\
& \left.\times\left[\xi_{2} J_{0}\left(q_{n} r\right)-\xi_{3} Y_{0}\left(q_{n} r\right)\right]\right\}
\end{aligned}
$$

where

$$
u(z)=\left[f_{m}(z)\left(k_{m_{0}}-k_{c_{0}}\right)+k_{c_{0}}\right], \quad f_{m}(z)=1-z^{\beta} .
$$

Using the solution of heat conduction Eq. (1) given by Eq. (29), the solution for the Goodier's thermoelastic displacement potential $\phi$ from Eq. (10) is obtained as

$$
\begin{gathered}
\phi=\left\langle\left[\alpha_{0}(1+v) /(1-v)\right] g_{1}(z) z^{\beta} \exp (\chi T)\right\rangle \\
\times\left\langle\begin{array}{c}
T_{0}+\sum_{n=1}^{\infty}\left[1 / \exp \left(\varpi T_{0}\right)\right] \times[1 / u(z)] \\
\left\{\sum_{m=1}^{\infty}\left\{\left(\left[\xi_{1}(t)\right]_{m=0} / h\right)+\sum_{m=1}^{\infty}\left\{\xi_{1}(t) \times \cos (m \pi z / h)\right\}\right\}\right. \\
\left.\times\left[\xi_{2} J_{0}\left(q_{n} r\right)-\xi_{3} Y_{0}\left(q_{n} r\right)\right]\right\}
\end{array}\right\rangle
\end{gathered}
$$

where

$$
g_{1}(z)=\frac{g_{2}(z)}{-q_{n}^{2} g_{2}(z)+g_{2}^{\prime \prime}(z)}, \quad g_{2}(z)=\frac{1+\cos (m \pi z / h)}{u(z)}
$$

We assume the Michell's function $M$ so as to satisfy Eq. (13) as

$$
\begin{aligned}
M= & \sum_{n=1}^{\infty} \sum_{m=1}^{\infty}\{\cos (\Omega z)] \exp \left(\psi_{1} t\right)\left[C_{n} J_{0}\left(q_{n} r\right)\right. \\
& \left.\left.+D_{n} r Y_{0}\left(q_{n} r\right)\right]\right\}
\end{aligned}
$$

where $C_{n}$ and $D_{n}$ are constants.

Using the values of $\phi$ and $M$ in Eq. (12), the displacement components are obtained as $u=\sum_{n=1}^{\infty} \sum_{m=1}^{\infty}\left\{\phi_{, r}-[-\Omega \sin (\Omega z)] \exp \left(\psi_{1} t\right)\right.$

$\times\left[-C_{n} q_{n} J_{1}\left(q_{n} r\right)-D_{n} r q_{n} Y_{1}\left(q_{n} r\right)\right.$

$\left.\left.+D_{n} Y_{0}\left(q_{n} r\right)\right]\right\}$

$w=\sum_{n=1}^{\infty} \sum_{m=1}^{\infty}\left\{\phi_{, z}+[(2-2 v)[\cos (\Omega z)]\right.$

$\times \exp \left(\psi_{1} t\right) \times\left[-C_{n} q_{n}^{2} J_{0}\left(q_{n} r\right)\right.$

$\left.\left.+D_{n} Y_{0}\left(q_{n} r\right)\left((1 / r)-q_{n} r\right)\right]\right]$

$+\left[(1-2 v)\left[\left(-\Omega^{2}\right) \cos (\Omega z)\right] \exp \left(\psi_{1} t\right)\right.$

$\left.\left.\times\left[C_{n} J_{0}\left(q_{n} r\right)+D_{n} r Y_{0}\left(q_{n} r\right)\right]\right]\right\}$

where a comma denotes differentiation with respect to the following variable.

Using Eqs. (32) and (33) in Eq. (14), the components of stresses in the homogeneous (by taking $\beta=\varpi=\chi=0$ ) as well as nonhomogeneous case (by taking $\beta \neq \varpi \neq \chi \neq 0$ ) can be obtained. Also by using, the traction free conditions given by Eq. (15) the constants $C_{n}$ and $D_{n}$ are determined (using Mathematica software).

\section{Numerical Results and Discussion}

Following [9], we consider a model of a ceramicmetal-based FGM, in which alumina is selected as the ceramic and nickel as the metal.

Table 1. Thermo-mechanical properties of alumina and nickel at room temperature.

\begin{tabular}{lcc}
\hline Property & $\begin{array}{c}\text { Alumina } \\
\text { (Ceramic) }\end{array}$ & $\begin{array}{c}\text { Nickel } \\
\text { (Metal) }\end{array}$ \\
\hline $\begin{array}{l}\text { Thermal conductivity } \\
k[\mathrm{~W} / \mathrm{cmK}]\end{array}$ & 0.282 & 0.901 \\
$\begin{array}{l}\text { Specific heat capacity } \\
C[\mathrm{~J} / \mathrm{gK}]\end{array}$ & 0.78 & 0.44 \\
$\begin{array}{l}\text { Shear modulus } G \\
{\left[\mathrm{~N} / \mathrm{cm}^{2}\right]}\end{array}$ & $12.4 \times 10^{6}$ & $7.6 \times 10^{6}$ \\
$\begin{array}{l}\text { Thermal expansion } \\
\text { coefficient }\end{array}$ & & \\
$\alpha\left[\times 10^{-6} / \mathrm{K}\right]$ & 5.4 & 14.0 \\
Poisson's ratio $v$ & 0.23 & 0.31 \\
\hline
\end{tabular}

Mathematica software is used for numerical computations and the following nondimensional parameters are used:

$T^{*}=\frac{T}{T_{0}}, \quad \eta=\frac{r}{a}, \quad \zeta=\frac{z}{a}$,

$\tau=\frac{\kappa t}{a^{2}}, \quad(\bar{u}, \bar{w})=\frac{(u, w)}{K_{0} T_{0} a}, K_{0}=\frac{1+v}{1-v} \alpha_{0}$,

$\left(\bar{\sigma}_{r r}, \bar{\sigma}_{\theta \theta}, \bar{\sigma}_{z z}, \bar{\sigma}_{r z}\right)=\frac{\left(\sigma_{r r}, \sigma_{\theta \theta}, \sigma_{z z}, \sigma_{r z}\right)}{G_{0} \alpha_{0} T_{0}}$

with parameters $a=1 \mathrm{~cm}, b=2 \mathrm{~cm}, h=1 \mathrm{~cm}$, and surrounding temperature $T_{0}=320^{\circ} \mathrm{K}$. 

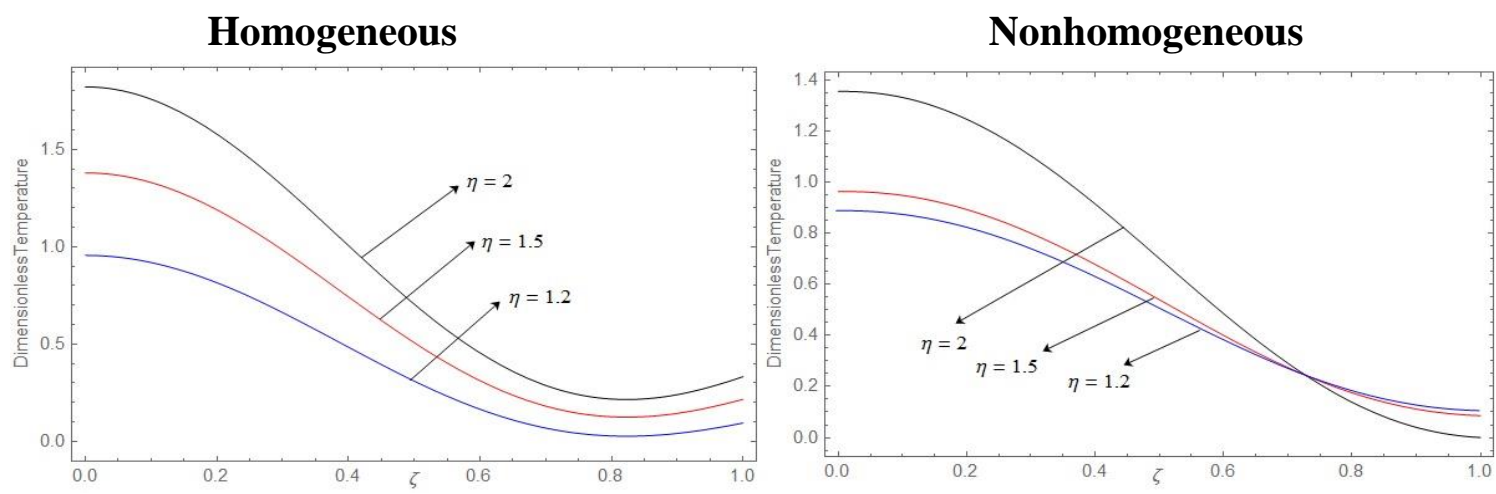

Figure 2. Variation of dimensionless temperature along axial direction.
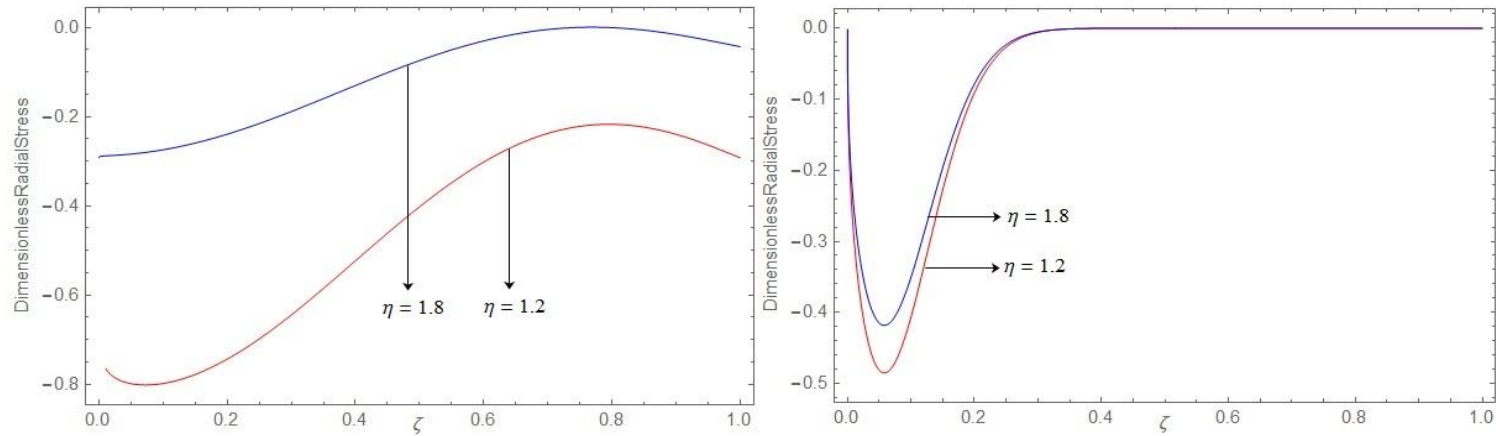

Figure 3. Variation of dimensionless radial stress along axial direction.
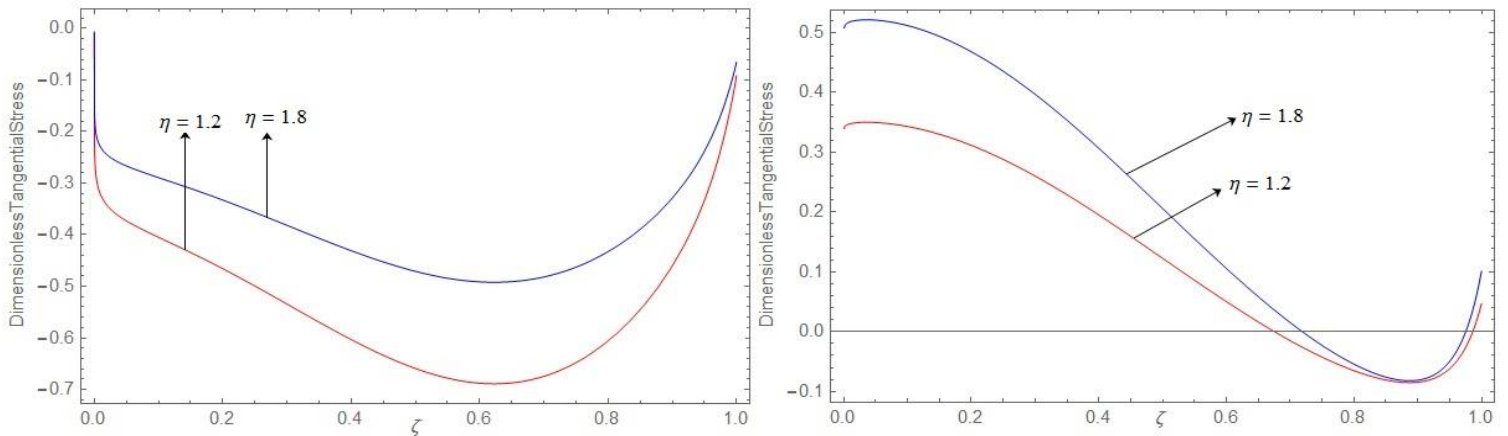

Figure 4. Variation of dimensionless tangential stress along axial direction.
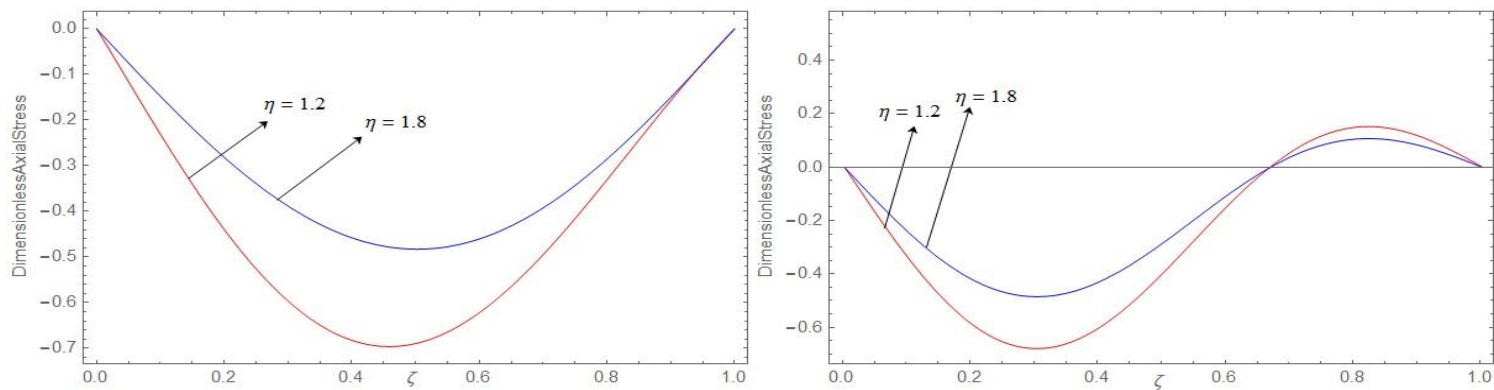

Figure 5. Variation of dimensionless axial stress along axial direction.
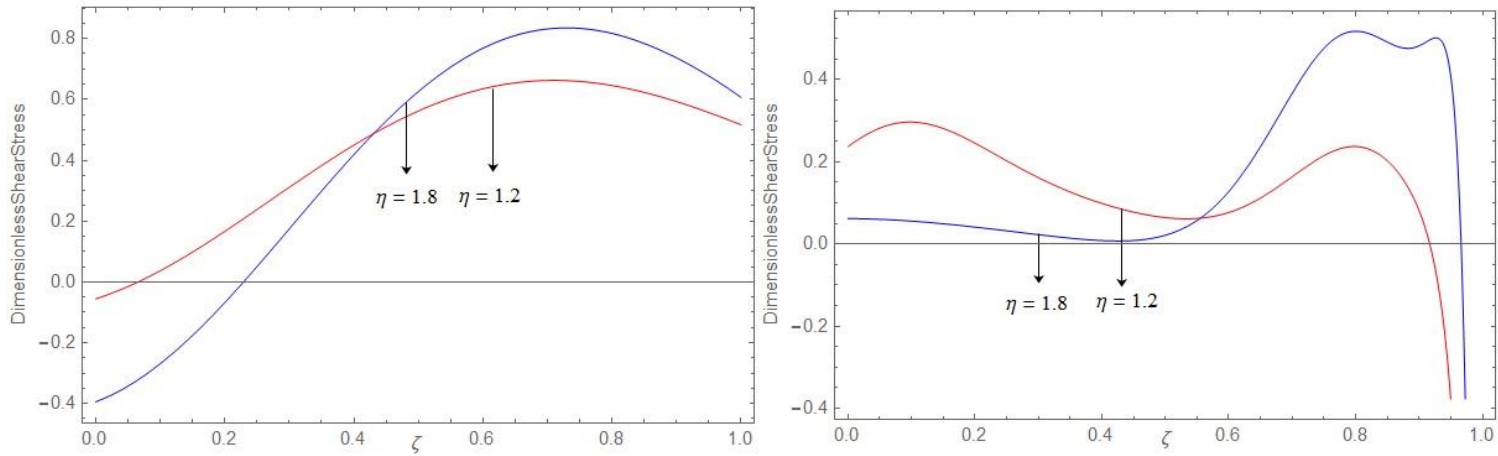

Figure 6. Variation of dimensionless shear stress along axial direction. 

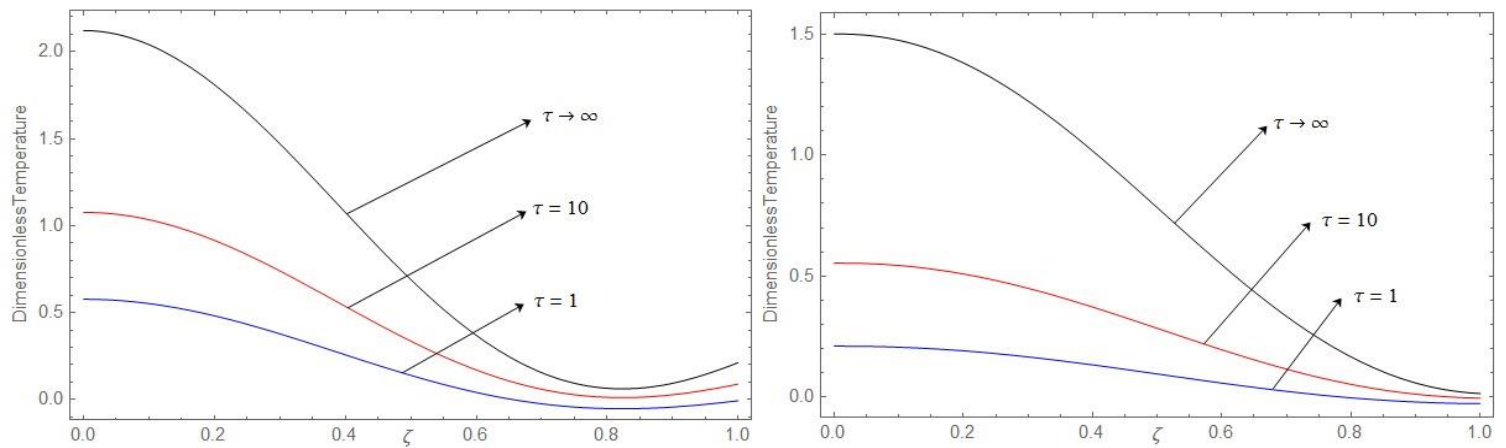

Figure 7. Variation of dimensionless temperature along axial direction for different time.
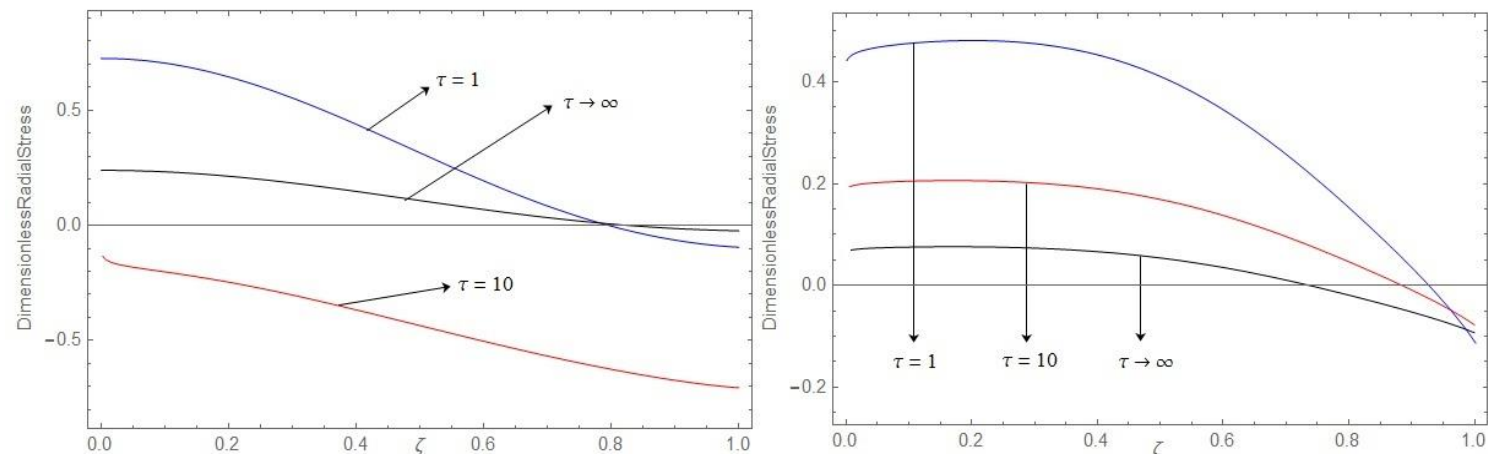

Figure 8. Variation of dimensionless radial stress along axial direction for different time.
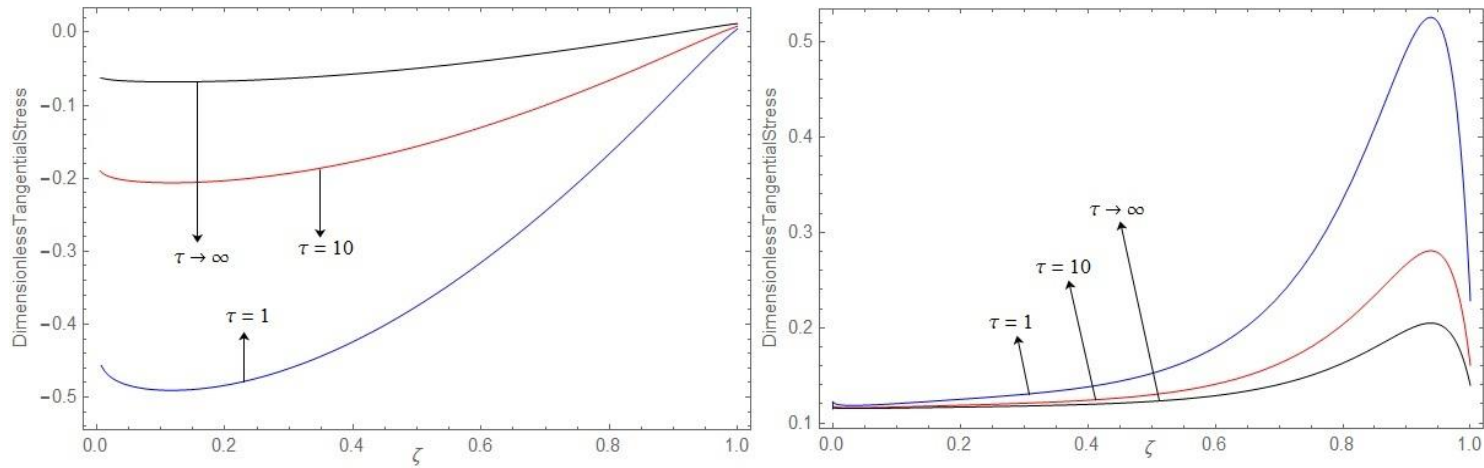

Figure 9. Variation of dimensionless tangential stress along axial direction for different time.
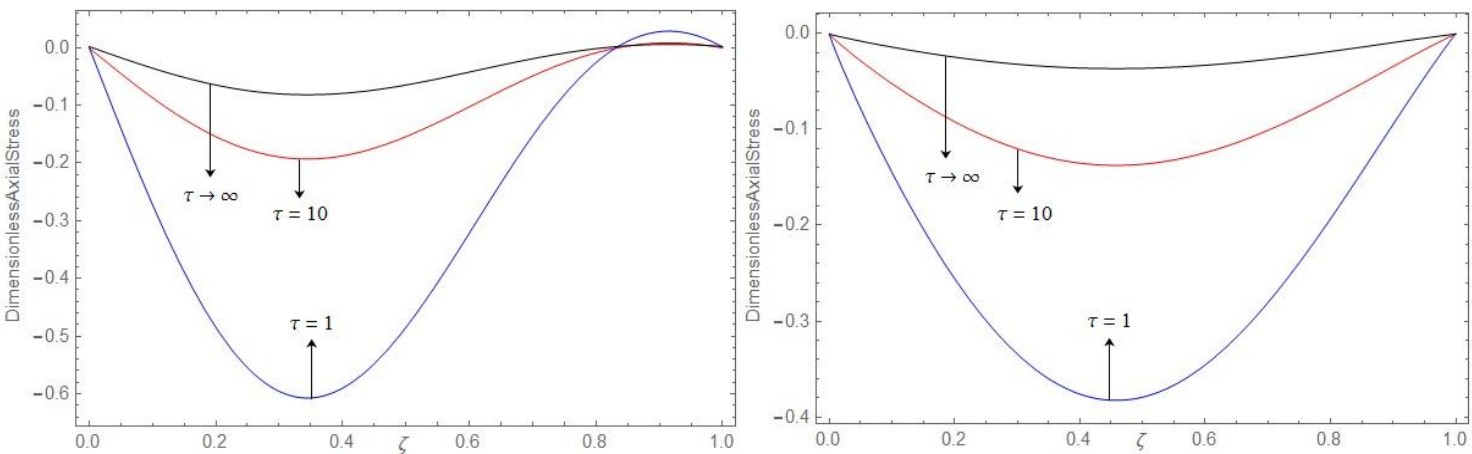

Figure 10. Variation of dimensionless axial stress along axial direction for different time.
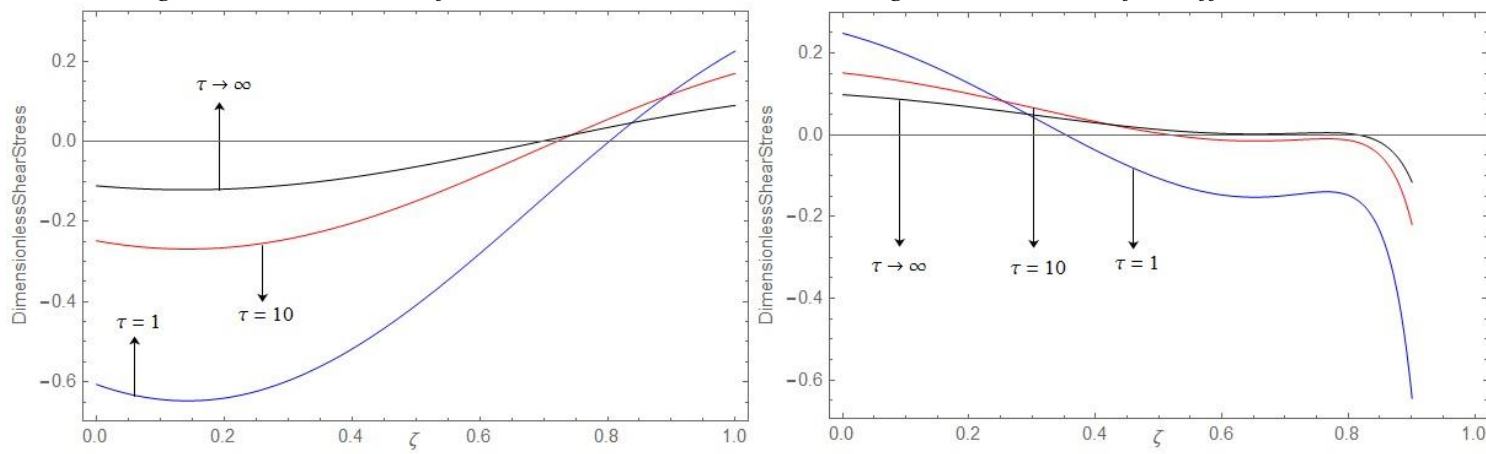

Figure 11. Variation of dimensionless shear stress along axial direction for different time. 
The above figures $2-11$ on the left are plotted for homogeneous hollow cylinder (i.e. taking $\beta, \varpi, \chi=0$, so that the material properties become independent of temperature and spatial variable), whereas the figures on the right are plotted for nonhomogeneous hollow cylinder (i.e. taking $\beta, \varpi, \chi \neq 0$, so that the material properties become dependent of temperature and spatial variable).

Figure 2 shows the variation of dimensionless temperature along axial direction for different values of $\eta=1.2,1.5,2$. In both the homogeneous and nonhomogeneous cases, it is seen that there is some temperature at the lower surface of the cylinder due to the application of varying point heat. The absolute value of temperature is slowly decreasing towards the upper surface of the cylinder. The magnitude of temperature is low for the nonhomogeneous case as compared to that of homogeneous case.

Figure 3 shows the variation of dimensionless radial stress along axial direction for different values of $\eta=1.2,1.8$. In the homogeneous case, the radial stress is compressive throughout the cylinder. In the nonhomogeneous case, the radial stress is compressive throughout the cylinder. Its magnitude is decreasing near the lower surface till $\zeta=0.1$, while suddenly increasing in the region $0.1<\zeta<0.25$.

Figure 4 shows the variation of dimensionless tangential stress along axial direction for different values of $\eta=1.2,1.8$. In the homogeneous case, the radial stress is compressive throughout the cylinder. Its magnitude is decreasing till $\zeta=0.7$ and increasing towards the upper surface. In the nonhomogeneous case, the tangential stress is tensile throughout the cylinder except in the region $0.7<\zeta<1$, where it is compressive.

Figure 5 shows the variation of dimensionless axial stress along axial direction for different values of $\eta$. In both the homogeneous and nonhomogeneous cases, the nature of the graph is sinusoidal. In the homogeneous case, the axial stress is compressive throughout the cylinder. Its magnitude is decreeing till the central region and increasing towards the upper surface. In the nonhomogeneous case, the axial stress is compressive in the region $0<\zeta<0.65$, while tensile in the region $0.65<\zeta<1$.

Figure 6 shows the variation of dimensionless shear stress along axial direction for different values of $\eta$. In the homogeneous case, the shear stress is compressive near the lower surface, whereas tensile in the region remaining region of the cylinder. In the nonhomogeneous case, the shear stress is tensile throughout the cylinder, except near the upper surface where it is compressive. Its magnitude is more or less steady till $\zeta=0.6$, while sudden increase near the upper surface is seen and peak value is attained at $\zeta=0.85$.

Figure 7 shows the variation of dimensionless temperature along axial direction for different values dimensionless time $\tau$. In both the homogeneous and nonhomogeneous cases, it is seen that the absolute value of temperature is slowly decreasing from the lower towards the upper surface of the cylinder. Also with increase in time, the magnitude of temperature is increasing.

Figures 8 and 9 respectively shows the variation of dimensionless radial stress and tangential stress along axial direction for different values dimensionless time $\tau$. As the time increases, it is seen that the stresses are decreasing. Figures 10 and 11 respectively shows the variation of dimensionless axial stress and shear stress along axial direction for different values dimensionless time $\tau$. The axial stress is compressive throughout the cylinder in both homogeneous and nonhomogeneous cases and its magnitude is decreasing with increase in time. In the homogenous case, the shear stress is compressive in the region $0<\zeta<0.7$, while tensile towards the upper surface. Whereas in the nonhomogeneous case it is tensile from the lower surface towards the middle portion, while compressive towards the upper surface.

\section{Validation of the Results}

In this paper, a mathematical model has been prepared by taking temperature and spatial variable dependent material properties and temperature distribution and its corresponding thermal stress distributions are obtained.

Following Manthena and Kedar [31], let us consider the following initial and boundary conditions:

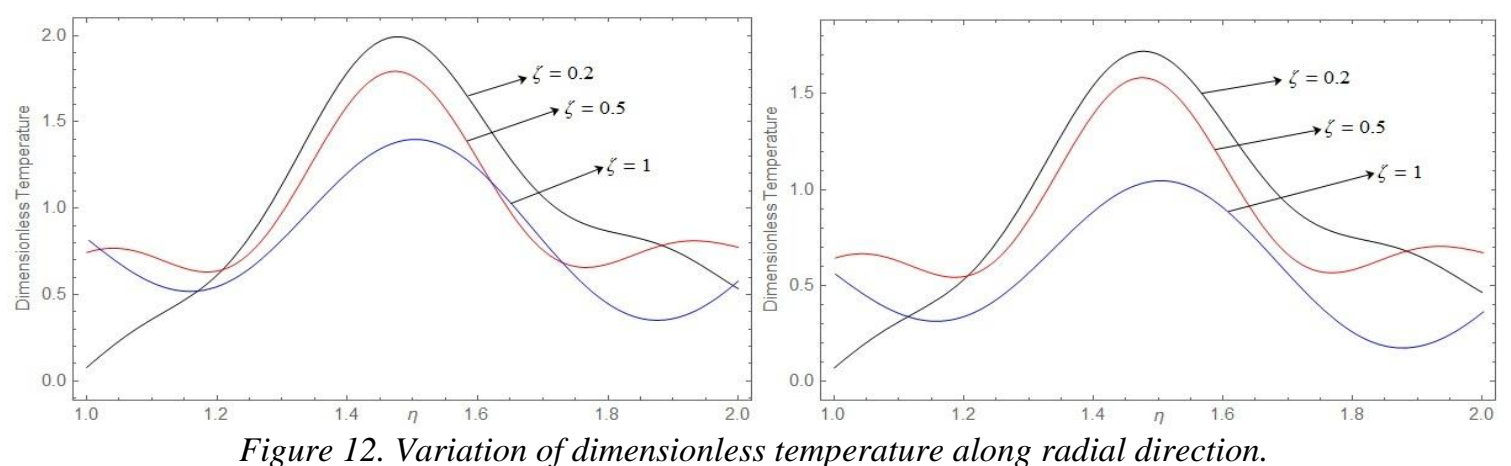



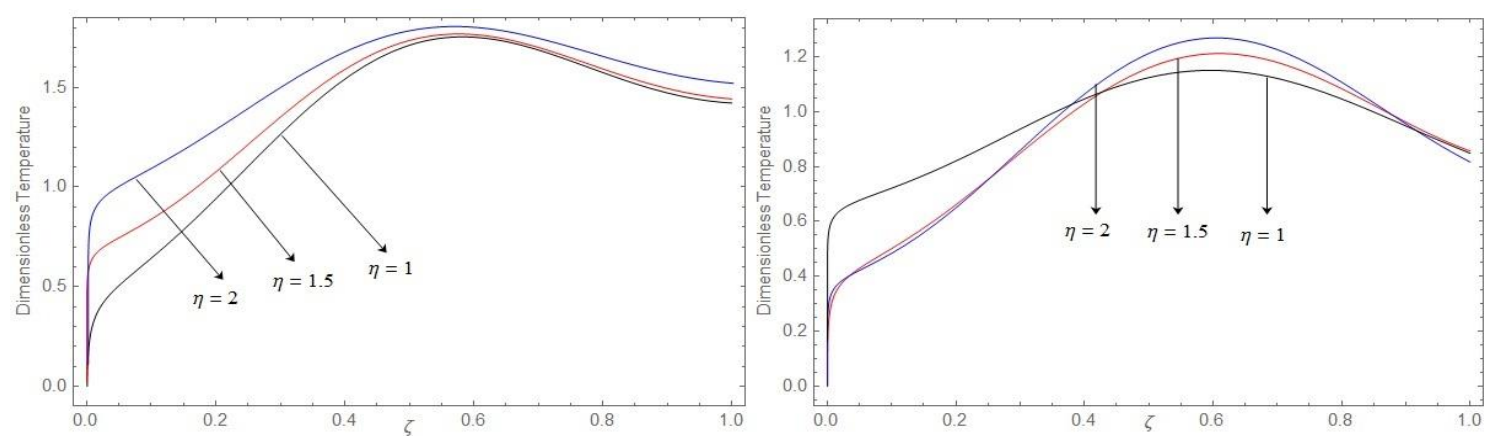

Figure 13. Variation of dimensionless temperature along axial direction.

$$
\begin{array}{ll}
T=T_{0}, & \text { at } t=0 \\
k(z, T) \frac{\partial T}{\partial r}-\varepsilon_{1}\left(T-T_{0}\right)=f_{1}(z, t), & \text { at } r=a \\
k(z, T) \frac{\partial T}{\partial r}+\varepsilon_{2}\left(T-T_{0}\right)=f_{1}(z, t), & \text { at } r=b \\
k(z, T) \frac{\partial T}{\partial z}-\varepsilon_{3}\left(T-T_{0}\right)=f_{2}(r, t), & \text { at } z=0 \\
k(z, T) \frac{\partial T}{\partial z}+\varepsilon_{4}\left(T-T_{0}\right)=0, & \text { at } z=h
\end{array}
$$

where

$f_{1}(z, t)=Q_{1} \delta\left(z-z_{0}\right) \sinh \left(\omega_{1} t\right)$,

$f_{2}(r, t)=Q_{2} \delta\left(r-r_{0}\right) \sinh \left(\omega_{1} t\right)$.

The solution of heat conduction Eq. (1) with $g(r, z, t)=0$, subjected to conditions (34) on applying the transform given by Al-Hajri and Kalla [11] and Laplace transform, is

$$
\begin{aligned}
& T(r, z, t) \cong T_{0}+\sum_{n=1}^{\infty} \sum_{m=1}^{\infty}\left\{\left[1 / \exp \left(\varpi T_{0}\right)\right]\right. \\
& \times[1 / u(z)] \times \xi_{1}(t) \\
& \times\left[\xi_{2} J_{0}\left(\alpha_{m} z\right)-\xi_{3} Y_{0}\left(\alpha_{m} z\right)\right] \\
& \left.\times\left[\xi_{4} J_{0}\left(q_{n} r\right)-\xi_{5} Y_{0}\left(q_{n} r\right)\right]\right\} \\
& \text { where } \\
& u(z)=\left[f_{m}(z)\left(k_{m_{0}}-k_{c_{0}}\right)+k_{c_{0}}\right], \\
& f_{m}(z)=1-z^{\beta}, \\
& \xi_{1}(t)=\left[E_{1} \exp \left(-A_{3} t\right)+E_{2} \exp (-\omega t)+E_{3} \exp (\omega t)\right], \\
& \xi_{2}=\left(1 /\left[N\left(\alpha_{m}\right)\right]\right)\left[D\left(0,-\varepsilon_{3}\right)+D\left(\alpha_{m} h, \varepsilon_{4}\right)\right], \\
& \xi_{3}=\left(1 /\left[N\left(\alpha_{m}\right)\right]\right)\left[C\left(0,-\varepsilon_{3}\right)+C\left(\alpha_{m} h, \varepsilon_{4}\right)\right], \\
& \xi_{4}=\left(1 /\left[M\left(q_{n}\right)\right]\right)\left[B\left(q_{n} a,-\varepsilon_{1}\right)+B\left(q_{n} b, \varepsilon_{2}\right)\right], \\
& \xi_{5}=\left(1 /\left[M\left(q_{n}\right)\right]\right)\left[A\left(q_{n} a,-\varepsilon_{1}\right)+A\left(q_{n} b, \varepsilon_{2}\right)\right] .
\end{aligned}
$$

The following Figures (12) and (13) represent the temperature distribution obtained in Eq.(35) in both homogeneous (Left) and nonhomogenous (Right) cases.

Hence, as a limiting case if we consider conditions (34) and the heat conduction Eq.(1) without internal heat generation, the temperature distribution and its graph obtained so well agrees with our paper [31].

\section{Conclusions}

In this study, the temperature distribution of a thick hollow cylinder with instantaneous point heat source has been determined with temperature and spatial variable dependent material properties. The thermoelastic behavior of an FGM model has been discussed. Numerical computations are carried out for ceramic-metal-based FGM, in which alumina is selected as ceramic and nickel as metal. Notable effects on the behavior of unsteady state temperature distribution is seen in the results due to thermally sensitive thermoelastic properties. During the investigation, it is seen that the magnitude of temperature distribution and all stresses is low for the nonhomogeneous case (FGM model) as compared to that of homogeneous case. Since the heating at inner curved surface exponentially varies with time, the temperature distribution increases as time increases, but the nature of temperature distribution remains nearly same and the same is happening with other thermoelastic quantities. Due to internal heat generation, it is observed that high compressive radial stress is developed in the lower part of the cylinder. Axial stress is tensile towards the outer surface. The proposed mathematical model may be useful in the chemical and physical characterization of materials, the kinetics of reactions, the thermodynamic properties and phase equilibria of systems, the development of new processing methods, and ultimately, the use of materials in advanced technology applications at high temperatures.

\section{Appendix A}

The volume fraction distribution of metal obeying simple power law with exponent $\beta$ is given as Awaji et al. [11]

$f_{m}(z)=1-z^{\beta}$ for $\beta \geq 0$

where $f_{m}(z)$ is the local volume fraction of metal in a functionally graded material and $\beta$ is a parameter that describes the volume fraction of metal.

The thermal conductivity of the functionally graded material is expressed using the thermal conductivities of metals $k_{m}$ and of ceramics $k_{c}$ with the volume fractions of metals $f_{m}(z)$, and ceramics, $1-f_{m}(z)$ as follows:

$$
k(z, T)=k_{m}(T) f_{m}(z)+k_{c}(T)\left(1-f_{m}(z)\right)
$$

Inverse Transformation: We substitute equation (A2) in Eq.(18) to obtain the inverse transformation of Eq.(18) as

$\Theta(T)=\int_{T_{0}}^{T}\left(k_{m}(T) f_{m}(z)+k_{c}(T)\left(1-f_{m}(z)\right) d T\right.$ 
$\Theta(T)=f_{m}(z)$

$\left.\times \int_{T_{0}}^{T} k_{m}(T) d T+\left(1-f_{m}(z)\right) \int_{T_{0}}^{T} k_{c}(T)\right) d T$

Following Noda [3], we assume the thermal conductivity of the hollow cylinder as $k(T)=k_{0} \exp (\varpi T)$ Hence, Eq. (A4) becomes

$$
\Theta=(1 / \varpi)\left[\left[\exp (\varpi T)-\exp \left(\varpi T_{0}\right)\right] u(z)\right]
$$

where

$u(z)=\left[f_{m}(z)\left(k_{m_{0}}-k_{c_{0}}\right)+k_{c_{0}}\right]$

Using Eq.(A5) in Eq.(28), we obtain

$$
\begin{aligned}
& T(r, z, t)=\frac{1}{\varpi} \log _{e}\left[F(r, z, t)+\exp \left(\varpi T_{0}\right)\right] \\
& =\frac{1}{\varpi} \log _{e}\left[\exp \left(\varpi T_{0}\right)\left(1+\frac{F(r, z, t)}{\exp \left(\varpi T_{0}\right)}\right)\right]
\end{aligned}
$$

where

$$
\begin{aligned}
F(r, z, t)= & \sum_{n=1}^{\infty}[1 / u(z)]\left\{\left(\left[\xi_{1}(t)\right]_{m=0} / h\right)\right. \\
& +\sum_{m=1}^{\infty}\left\{\xi_{1}(t) \times \cos (m \pi z / h)\right\} \\
& \left.\times\left[\xi_{2} J_{0}\left(q_{n} r\right)-\xi_{3} Y_{0}\left(q_{n} r\right)\right]\right\}
\end{aligned}
$$

We use the following logarithmic expansion

$$
\begin{aligned}
\log _{e}[ & \left.\left(F(r, z, t) / \exp \left(\varpi T_{0}\right)\right)+1\right]= \\
& {\left[F(r, z, t) / \exp \left(\varpi T_{0}\right)\right] } \\
+ & (1 / 2)\left[(F(r, z, t)) / \exp \left(\varpi T_{0}\right)\right]^{2} \\
& +(1 / 3)\left[(F(r, z, t)) / \exp \left(\varpi T_{0}\right)\right]^{3} \\
& +(1 / 4)\left[(F(r, z, t)) / \exp \left(\varpi T_{0}\right)\right]^{4}+\ldots . .
\end{aligned}
$$

We observe that $[F(r, z, t)]^{m}$ given in Eq.(A7) converges to zero as $m$ tends to infinity. In addition, the truncation error in Eq.(A8) is observed as $4.037 \times 10^{-5}$.

Hence, for the sake of brevity, neglecting the terms with order more than one, we obtain:

$$
\begin{aligned}
& \log _{e}\left[\left(F(r, z, t) / \exp \left(\varpi T_{0}\right)\right)+1\right] \\
& \cong\left[F(r, z, t) / \exp \left(\varpi T_{0}\right)\right]
\end{aligned}
$$

Hence Eq. (A6) becomes

$$
\begin{aligned}
T(r, z, t) \cong & T_{0}+\sum_{n=1}^{\infty}[1 / u(z)]\left\{\left(\left[\xi_{1}(t)\right]_{m=0} / h\right)\right. \\
& +\sum_{m=1}^{\infty}\left\{\xi_{1}(t) \times \cos (m \pi z / h)\right\} \\
& \left.\times\left[\xi_{2} J_{0}\left(q_{n} r\right)-\xi_{3} Y_{0}\left(q_{n} r\right)\right]\right\}
\end{aligned}
$$

\section{References}

[1] S. Tang, Thermal stresses in temperature dependent isotropic plates, J. Spacecrafts and Rockets, 5, 987990, 1968.

[2] T. Hata, "Thermal stresses in a nonhomogeneous thick plate under steady distribution of temperature", Journal Thermal Stresses, 5, 1-11, 1982.
[3] N. Noda, "Thermal stresses in materials with temperature dependent properties", Thermal Stresses I, Taylor \& Francis, North Holland, Amsterdam, 391483, 1986.

[4] Y. Obata and N. Noda, "Unsteady thermal stresses in functionally gradient Material Plate (influence of heating and cooling conditions on unsteady thermal stresses)", Trans. JSME A, 59, 1097-1103, 1993.

[5] V.S. Popovych and G.Yu. Garmatii, "Analyticnumerical methods of constructing solutions of heatconduction problems for thermosensitive bodies with convective heat transfer" [in Ukrainian], Ukrainian Academy of Sciences, Pidstrigach Institute for Applied Problems of Mechanics and Mathematics, L'viv, Ukraine, Preprint, 13-93, 1993.

[6] V.S. Popovych and B.N. Fedai, The axisymmetric problem of thermoelasticity of a multilayer thermosensitive tube, Journal Mathematical Sciences, 86, 2605-2610, 1997.

[7] N. Noda, "Thermal stresses in functionally graded materials", Journal Thermal Stresses, 22, 477-512, 1999.

[8] Y. Miyamoto, W.A. Kaysser, B.H. Rabin, B.H., A. Kawasaki, and R.G. Ford, R.G., "Functionally Graded Materials: Design, Processing and Applications", Kluwer Academic, Boston, 1999.

[9] H. Awaji, H. Takenaka, S. Honda and T. Nishikawa, "Temperature/Stress distributions in a stress-relief-type plate of functionally graded materials under thermal shock", JSME Int. J., 44, 37 44, 2001.

[10] A. Kawasaki and R. Watanabe, "Thermal fracture behavior of metal/ceramic functionally graded materials", Eng. Fract. Mech., 69, 1713-1728, 2002.

[11] M. Al-Hajri and S.L. Kalla, "On an integral transform involving Bessel functions", Proceedings of the international conference on Mathematics and its applications, Kuwait, April 5-7, 2004.

[12] R. Kushnir and V.S. Popovych, Thermoelasticity of thermosensitive solids, SPOLOM, Lviv, 2009.

[13] Li-C. Guo and N. Noda, "An analytical method for thermal stresses of a functionally graded material cylindrical shell under a thermal shock", Acta Mechanica, 214, 71-78, 2010.

[14] G.D. Kedar and K.C. Deshmukh, "Estimation of temperature distribution and thermal stresses in a thick circular plate", African J. Mathematics and Computer Science Research, 4, 389-395, 2011.

[15] R. Kushnir and V.S. Popovych, Heat conduction problems of thermosensitive solids under complex heat exchange, INTECH, 2011.

[16] R.M. Mahamood, E.T. Akinlabi, M. Shukla, and S. Pityana, "Functionally Graded Material: An Overview", Proceedings of the World Congress on Engineering 2012, Vol III, July 4 - 6, London, U.K, 2012.

[17] J.N. Sharma, D. Sharma, and S. Kumar, "Stress and strain analysis of rotating FGM thermoelastic circular disk by using FEM", Int. J. Pure and Applied Mathematics, 74, 339-352, 2012.

[18] A. Moosaie, Axisymmetric steady temperature field in FGM cylindrical shells with temperaturedependent heat conductivity and arbitrary linear boundary conditions, Arch. Mech., 67, 233-251, 2015. 
[19] A.M. Nikolarakis, E.E. Theotokoglou, Transient stresses of a functionally graded profile with temperature-dependent materials under thermal shock, 8th GRACM Int. Congress on Computational Mechanics, Volos, Greece, 2015.

[20] A.N. Eraslan and T. Apatay, "Analytical solution to thermal loading and unloading of a cylinder subjected to periodic surface heating", J. Thermal Stresses, 39, 928-941, 2016.

[21] V.R. Manthena, N.K. Lamba, G.D. Kedar and K.C. Deshmukh, "Effects of stress resultants on thermal stresses in a functionally graded rectangular plate due to temperature dependent material properties", Int. J. Thermodynamics, 19, 235-242, 2016.

[22] I. Rakocha and V.S. Popovych, "The mathematical modeling and investigation of the stress-strain state of the three-layer thermosensitive hollow cylinder", Acta Mechanica et Automatica, 10, 181-188, 2016.

[23] V.R. Manthena, N.K. Lamba, and G.D. Kedar, Springbackward phenomenon of a transversely isotropic functionally graded composite cylindrical shell, J. Applied and Computational Mechanics, 2, 134-143, 2016.

[24] R. Kumar, V.R. Manthena, N.K. Lamba and G.D. Kedar, "Generalized thermoelastic axi-symmetric deformation problem in a thick circular plate with dual phase lags and two temperatures", Material Physics and Mechanics, 32, 123-132, 2017.

[25] P. Bhad, V. Varghese and L. Khalsa, "Transient thermal stresses of annulus elliptical plate with mixed-type boundary conditions", Int. J. Thermodynamics, 20, 26-34, 2017.
[26] A.K. Surana, K.J. Samuel, S. Harshit, U. Kumar and R.T.K. Raj, "Numerical investigation of shell and tube heat exchanger using $\mathrm{A} 12 \mathrm{O} 3$ nanofluid", Int. J. Thermodynamics, 20, 59-68, 2017.

[27] J.J.Tripathi, K.C. Deshmukh and J. Verma, "Fractional order generalized thermoelastic problem in a thick circular plate with periodically varying heat source", Int. J. Thermodynamics, 20, 132-138, 2017.

[28] V.R. Manthena, N.K. Lamba, and G.D. Kedar, "Transient thermoelastic problem of a nonhomogeneous rectangular plate", J. Thermal Stresses, 40, 627-640, 2017.

[29] U. Köbler, "On the thermal conductivity of metals and of insulators",Int. J. Thermodynamics, 20, 210218, 2017.

[30] V.R. Manthena, N.K. Lamba, and G.D. Kedar, "Thermal stress analysis in a functionally graded hollow elliptic-cylinder subjected to uniform temperature distribution", Applications and Applied Mathematics, 12, 613-632, 2017.

[31] V.R. Manthena and G.D. Kedar, "Transient thermal stress analysis of a functionally graded thick hollow cylinder with temperature dependent material properties", J. Thermal Stresses, 41, 568-582, 2018. 